\title{
Adsorption of Chiral Modifiers from Solution onto Supported \\ Platinum Catalysts: The Effect of the Solvent, Other Co-Adsorbates, and the Support
}

Yufei Ni, Zihao Wang, Ilkeun Lee, and Francisco Zaera*

Department of Chemistry and UCR Center for Catalysis University of California, Riverside, CA 92521 (USA)

* Corresponding Author, E-mail: zaera@ucr.edu

\section{Supporting Information}

Expanded versions of Figures 2 and 3, enlarged in the $1000-1800 \mathrm{~cm}^{-1}$ region. 


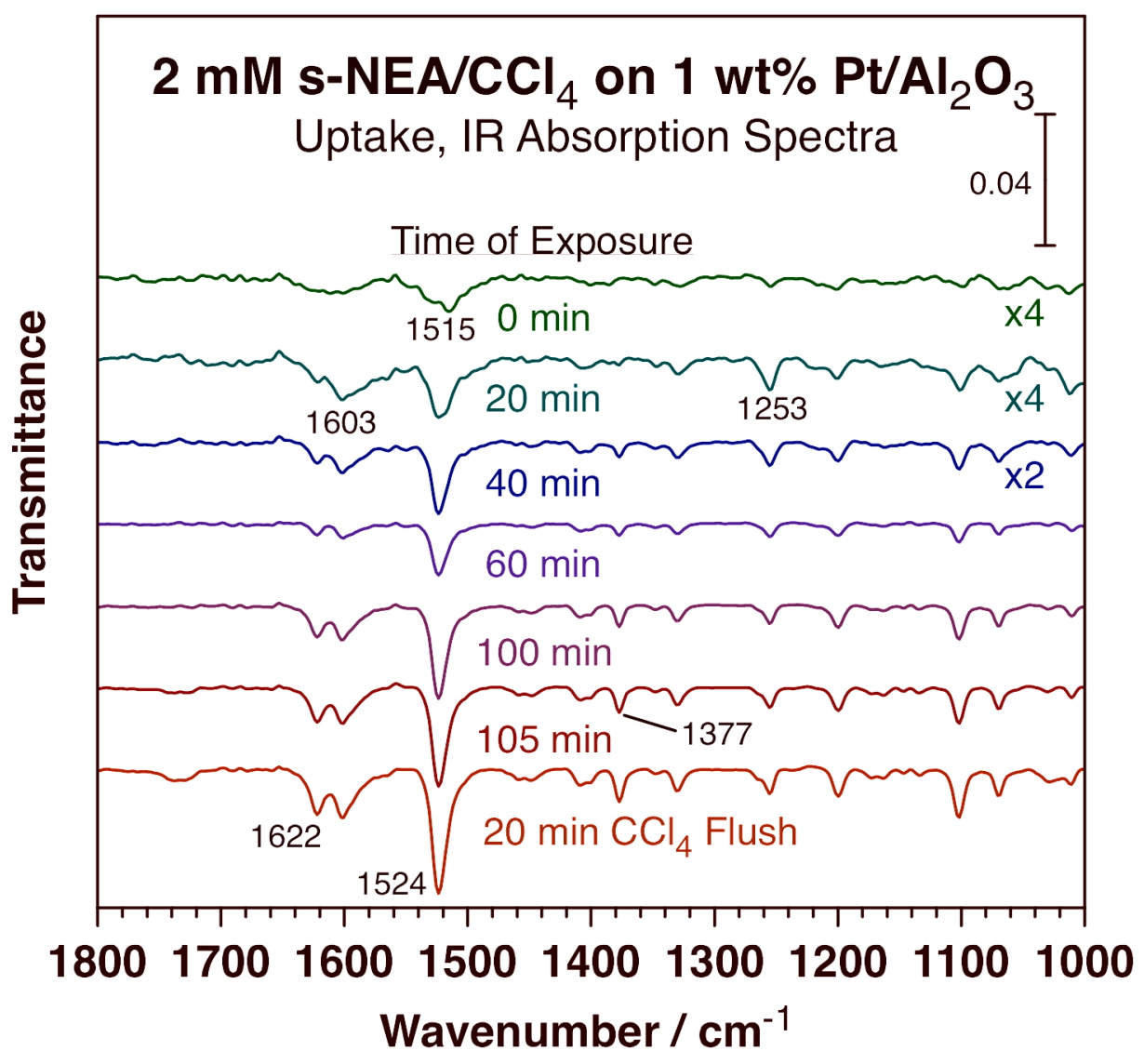

Figure S1. ATR-IR spectra of s-NEA adsorbed on $1 \mathrm{wt} \% \mathrm{Pt} / \mathrm{Al}_{2} \mathrm{O}_{3}$ from a $2 \mathrm{mM} \mathrm{CCl}$ solution as a function of the time of exposure of the surface to the liquid. Expanded version of Figure 2 in the 1000 $1700 \mathrm{~cm}^{-1}$ region, highlighting the peaks used in the discussion. 


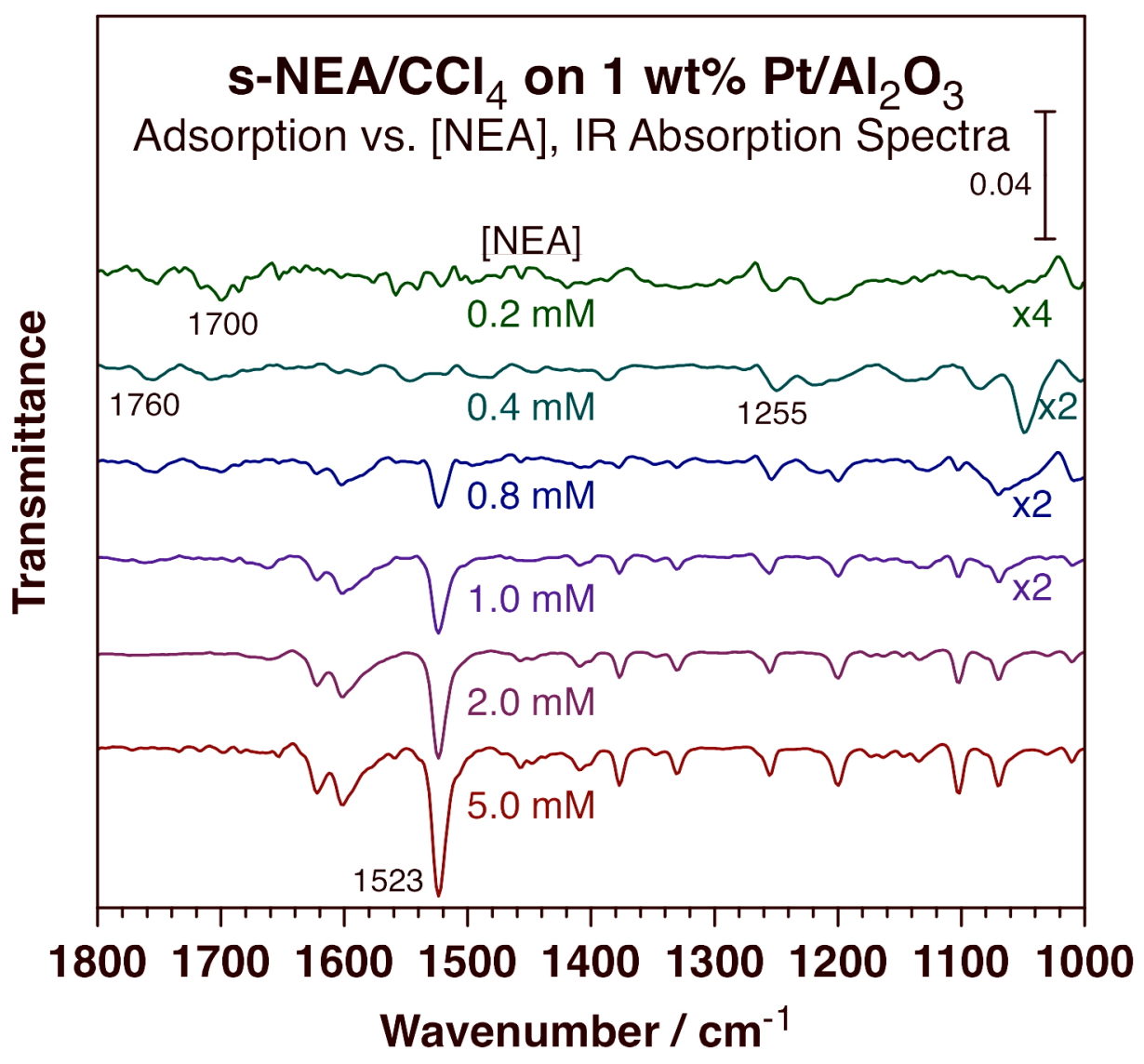

Figure S2. ATR-IR spectra of s-NEA adsorbed on $1 \mathrm{wt} \% \mathrm{Pt} / \mathrm{Al}_{2} \mathrm{O}_{3}$ as a function of concentration. $\mathrm{CCl}_{4}$ was used as the solvent in all cases. Expanded version of Figure 2 in the $1000-1700 \mathrm{~cm}^{-1}$ region, highlighting the peaks used in the discussion. 